\title{
The heart rate variability in autonomic stress testing in persons with undifferentiated connective tissue dysplasia
}

\author{
Akimova $\mathrm{AV}^{1}$, Mironov $\mathrm{VA}^{1}$, Mironova $\mathrm{TF}^{2 *}$, Khusainova $\mathrm{DF}^{1}$ and Tarasova $\mathrm{EV}^{1}$ \\ ${ }^{1}$ Ural State Medical University, Ekaterinburg, Russia \\ ${ }^{2}$ Federal Budget Scientific Institute “Ekaterinburg medical scientific Center of Prevention of Health Protection of Industrial Workers”, Ekaterinburg, Russia
}

\begin{abstract}
Connective tissue dysplasia (CTD), especially the undifferentiated form, is common among young people. External signs of connective tissue dysplasia and minor malformations are associated with somatic diseases, emotional disorders and autonomic dysfunction.

The aim of the study was to identify phenotypic, clinical, psychological manifestations and features of autonomic regulation in young people with undifferentiated connective tissue dysplasia (UCTD).

Method: We examined 67 young people aged 18-25 years. Clinical signs and symptoms of CTD were evaluated using standard methods. Pain intensity was measured by visual analog pain scale. Autonomic disorders were assessed using the Vein Questionnaire. The autonomic regulation was evaluated by heart rate variability (method of high resolution rhythmocardiography). All participants were divided into 2 groups. The UCTD group included persons with 6 or more external signs. The control group composed of participants who had less than 6 signs of CTD.

Result: The syndrome of undifferentiated connective tissue dysplasia (UCTD) was identified in $64.2 \%$ (43 participants). We found that young people (regardless of the presence of undifferentiated connective tissue dysplasia) more frequently had head pain. Arthralgia was significantly more common in patients with the UCTD syndrome. The psychological manifestations identified by the multilateral study of personality in participants with UCTD characterized by fewer scores on the scale of social introversion. The features of autonomic regulation of heart rate variability were found using the method of rhythmocardiography. The predominance of the parasympathetic regulation of sinus rhythm was reveled in young people with UCTD.
\end{abstract}

Conclusion: Young people with multiple signs of CTD differ significantly from the control group respect to clinical symptoms and psychoemotional state, and they have features of autonomic regulation of the heart rhythm.

\section{Introduction}

The name "connective tissue dysplasia" (CTD) covers a wide range of disorders. These disorders are caused by a weakness in the connective tissue including tissues such as bone, ligaments, tendons and skin. CTD is a genetically determined condition that affect the normal metabolism of connective tissue and the disruption of the structure of fibers and ground substance. The uniqueness of the structure and function of connective tissue creates the conditions for the emergence of a large number of anomalies and diseases caused by chromosomal and gene defects in the embryonic and postnatal periods and having a certain type of inheritance [1].

Depending on the characteristics of the etiological factor, it is advisable to allocate the hereditary disorders of connective tissue (differentiated or monogenic diseases) and the connective tissue dysplasia (undifferentiated forms -UCTD). The prevalence of hereditary forms is small. Thus, the frequency of Marfan syndrome in the population is 1:10000-1:15000. In contrast, UCTD is widespread in Russia: about $8.5 \%$ in the sample of 400 people.

According to the literature data, the prevalence of individual external signs is extremely high: single external signs are detected in $94 \%$ of persons of young age. The frequency of occurrence of UCTD among young people are contradictory, according to some scholars, they range from $13.0 \%$ to $85.4 \%[2,1]$.
There are the following clinical syndromes of UCTD: a syndrome of neurological disorders, asthenic, valve, thoracolumbalis, vascular, arrhythmic, respiratory, visceral syndrome, immunological disorders, eye pathology, pathology of the foot, hypermobility of joints, and disorders of the mental sphere [3-6].

Widespread UCTD with progressive nature of the disease and multiple organ destruction make it an important medical and social problem.

The aim of the study was to conduct a comprehensive evaluation of clinical, phenotypic characteristics and heart rate variability in persons with UCTD.

\section{Method}

We studied 67 young adults aged from 18 to 25 years. The research was conducted in " 5 th Military Clinical Hospital of National Guard Troops of the Russian Federation" in Ekaterinburg.

${ }^{\star}$ Correspondence to: Mironova TF, Federal Budget Scientific Institute, "Ekaterinburg medical scientific Center of Prevention of Health Protection of Industrial Workers", Ekaterinburg, Russia, E-mail: micor_mail@mail.ru

Key words: connective tissue disorders, pain, autonomic regulation, heart rate variability, rhythmocardiography (RCG)

Received: June 08, 2018; Accepted: June 22, 2018; Published: June 28, 2018 
The study based on voluntary participation and informed written consent. A total of 67 young people with a median $(25 \% \div 75 \%)$ age of $22(20 \div 23)$ years were enrolled in this study. Symptoms of CTD was identified in accordance National Recommendations of the Russian Scientific Society of Internal Medicine, 2016) [1]. We considered the following symptoms of UCTD: dolichostenomelia, arachnodactyly, Steinberg thumb sign and Walker-Murdoch wrist sign, protruding ears, "crumpled" ears, fused earlobe, high arched palate, dental crowding, malocclusions, diastema, lax joints, hyperextensibility of knees and elbows, hyperextensibility of thumbs and fingers, genu varum, genu valgum, flat foot, pes planovalgus, wide gap between the first and second toes, syndactyly of toes 2 and 3, short 1 toe, hallux valgus, alar chest, pectus excavatum or carinatum, scoliosis, winged scapula, straight back, hyperkyphosis, hyperlordosis, varicose veins, sclera blue, hypo/ hypertelorism, hyperextensible skin, skin striae distensae, multiple moles, depigmentation. We diagnosed UCTD if there were 6 signs and more. The severity of different pain syndromes was determined using a visual analog scale (VAS). The symptoms of autonomic dysfunction ware determined on the Vein score (A.M. Vein, 2003). If the Vein score is 15 and more, we recorded an autonomic dysfunction.

The participants were divided into 2 groups: main group and control group. In case of determining 6 signs and more, the examined were assigned to the main UCTD-group $(n=43)$; if the signs were less than 6 , the persons were included in the control group $(n=24)$.

We studied the heart rate variability (HRV) by rhythmocardiography (RCG). The examination was carried out on a computer diagnostic complex - CAP-RC-01-"Micor" (registration certificate № FS

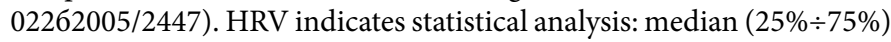
of the duration of RR-interval in seconds, standard deviation of all the waves from the mean RR (SDNN), standard deviation of each fluctuation: humoral-metabolic $(\sigma \mathrm{l})$, sympathetic $(\sigma \mathrm{m})$, parasympathetic ( $\sigma s)$ effects divisions of the autonomic system, and the average amplitude of respiratory arrhythmia (ARA). The ratio of the factors of regulation in the sinus node after the expansion wave structure of the HRV frequency components 3 in the program "Micor" presents the percentages of influence on the pacemaker: humoral- metabolic effects - in a very low frequency (VLF\%), sympathetic -in a low frequency (LF\%) and parasympathetic in a high frequency (HF\%); in the frequency ranges relative to the total spectrum, taken as $100 \%$. Recording was performed in the supine position (initial background RCG record), modified Valsalva maneuver ( Vm), Ashner-Dagnini test $(\mathrm{Pa})$, active orthostasic test (Aop), loading test is a modified PWC120 test (Power Working Capaciti) [7].

Differences between the groups were assessed using nonparametric Mann-Whitney U-test, the differences in the frequency of symptom groups were assessed using $\chi^{2}$ criterion, the significance of differences significant at $\mathrm{p}<0.05$.

\section{Results}

Signs of UCTD were detected among $100 \%$ of patients in different quantities. The frequency of detecting 6 and more UCTD-signs was $64.2 \%$ among young people. The results are shown in the Table1.

People with UCTD are significantly more likely to have the following characteristics: flat feet, Walker-Murdoch wrist sign, alar chest, hyperextensibility of thumbs, elbow joints and fingers, and Steinberg thumb sign $(\mathrm{p}<0.05)$. These signs can be considered the most important in the diagnosis of UCTD. We found the high incidence of fused earlobe and scoliosis. These symptoms are often comparable in both groups. There is a tendency towards a higher frequency of high arched palate, syndactyly of 2-3 toes, malocclusion, hypermobility of knee joints and multiple moles in the group of UCTD.

The main clinical characteristics of the compared groups are shown in the Table 2.

The groups did not differ by age, but the UCTD group had a significantly lower body mass index BMI $(\mathrm{p}=0.007)$. This may be related to muscle hypotrophy and lower bone density in UCTD cases. Patients with UCTD are more concerned about arthralgia ( $\mathrm{p}=0.037$ ). The frequency of pain at other sites in the study and control groups has no significant differences.

According to RCG, two groups were similar in the values RRintervals $(p=0.92)$. However, the UCTD-group showed higher values

Table 1. The frequency of connective tissue dysplasia signs among young people

\begin{tabular}{|c|c|c|c|c|c|}
\hline Signs & $\begin{array}{c}\text { Frequency of } \\
\text { detection }(n=67)\end{array}$ & $\begin{array}{r}\text { Group UCTD } \\
(n=43)\end{array}$ & Control Group $(n=24)$ & $\chi^{2}$ & $\mathbf{p}$ \\
\hline $\begin{array}{l}\text { Fused earlobe } \\
\text { Flat feet } \\
\text { Walker-Murdoch wrist sign } \\
\text { Scoliosis } \\
\text { Alar chest } \\
\text { Malocclusions } \\
\text { Hyperextensibility of thumbs } \\
\text { Steinberg thumb sign Hyperextensibility of elbows } \\
\text { Hyperextensibility of fingers } \\
\text { Wide gap between the first and second toes }\end{array}$ & $\begin{array}{l}26(38,8 \%) \\
\mathbf{2 6}(38,8 \%) \\
\mathbf{2 4}(35,8 \%) \\
23(34,3 \%) \\
\mathbf{2 2}(32,8 \%) \\
20(29,9 \%) \\
\mathbf{2 0}(29,9 \%) \\
\mathbf{1 9}(28,4 \%) \\
\mathbf{1 8}(26,9 \%) \\
\mathbf{1 7}(25,4 \%) \\
17(25,4 \%)\end{array}$ & \begin{tabular}{|l|}
16 \\
$\mathbf{2 3}$ \\
$\mathbf{2 3}$ \\
16 \\
$\mathbf{1 9}$ \\
17 \\
$\mathbf{1 9}$ \\
$\mathbf{1 7}$ \\
$\mathbf{1 8}$ \\
$\mathbf{1 6}$ \\
12
\end{tabular} & $\begin{array}{l}10 \\
3 \\
1 \\
7 \\
3 \\
3 \\
1 \\
2 \\
0 \\
1 \\
5\end{array}$ & $\begin{array}{c}0,09 \\
8,49 \\
13,46 \\
0,024 \\
5,21 \\
3,48 \\
9,3 \\
5,39 \\
11,8 \\
6,7 \\
0,093\end{array}$ & $\begin{array}{c}0,76 \\
\mathbf{0 , 0 0 4} \\
\mathbf{0 , 0 0 0} \\
0,88 \\
\mathbf{0 , 0 2 2} \\
0,063^{*} \\
\mathbf{0 , 0 0 2} \\
\mathbf{0 , 0 2} \\
\mathbf{0 , 0 0 0} \\
\mathbf{0 , 0 1} \\
0,76\end{array}$ \\
\hline
\end{tabular}

Table 2. Main clinical characteristics of the compared groups (Me, $25 \% \div 75 \%$ ).

\begin{tabular}{|c|c|c|c|}
\hline Signs & Group UCTD $(n=43)$ & Control Group $(n=24)$ & $\mathbf{p}$ \\
\hline Age, years & $22(20 \div 23)$ & $22,5(20 \div 25)$ & 0,120 \\
\hline BMI, $\mathrm{kg} / \mathrm{m}^{2}$ & $21,5(19,3 \div 22,8)$ & $22,8(21,8 \div 24,4)$ & 0,007 \\
\hline Vein score & $25,5(9,5 \div 37)$ & $15(3 \div 27)$ & 0,148 \\
\hline Joint pain, score & $1(0 \div 5)$ & $0(0 \div 0)$ & 0,037 \\
\hline Back pain, score & $2(0 \div 5)$ & $0(0 \div 3)$ & 0,144 \\
\hline Heart pain, score & $0(0 \div 2)$ & $0(0 \div 3)$ & 0,488 \\
\hline Headaches, score & $1,5(0 \div 4)$ & $1,5(0 \div 5)$ & 0,698 \\
\hline The chest pain, score & $0(0 \div 1)$ & $0(0 \div 1)$ & 0,825 \\
\hline Abdominal pain, score & $0(0 \div 2)$ & $0(0 \div 2)$ & 0,810 \\
\hline
\end{tabular}


Table 3. The parameters of heart rate variability in persons with undifferentiated connective tissue dysplasia (Me, $25 \% \div 75 \%$ ).

\begin{tabular}{|c|c|c|c|c|}
\hline Tests & Signs & Group UCTD(n=38) & Control Group $(\mathbf{n}=\mathbf{2 0})$ & $\mathbf{p}$ \\
\hline \multirow{5}{*}{$\mathrm{ph}$} & RR & $0.831(0.767 \div 0.995)$ & $0.846(0.799 \div 0.947)$ & 0.92 \\
\hline & SDNN & $0.046(0.039 \div 0.06)$ & $0.043(0.03 \div 0.05)$ & 0.28 \\
\hline & ARA & $0.081(0.056 \div 0.114)$ & $0.061(0.042 \div 0.093)$ & 0.14 \\
\hline & $\sigma s$ & $0.03(0.021 \div 0.044)$ & $0.023(0.015 \div 0.036)$ & 0.18 \\
\hline & $\mathrm{HF} \%$ & $43.9(27.8 \div 64.4)$ & $41.5(22.7 \div 34.1)$ & 0.47 \\
\hline \multirow{3}{*}{$\mathrm{Vm}$} & ARA & $0.067(0.054 \div 0.087)$ & $0.049(0.036 \div 0.08)$ & 0.036 \\
\hline & $\sigma s$ & $0.025(0.02 \div 0.034)$ & $0.018(0.013 \div 0.031)$ & 0.056 \\
\hline & $\mathrm{HF} \%$ & $40.35(27.3 \div 54.5)$ & $29.6(18.8 \div 41.3)$ & 0.12 \\
\hline \multirow{4}{*}{$\mathrm{Pa}$} & ARA & $0.074(0.049 \div 0.097)$ & $0.048(0.033 \div 0.071)$ & 0.07 \\
\hline & $\sigma \mathrm{s}$ & $0.028(0.019 \div 0.039)$ & $0.02(0.012 \div 0.028)$ & 0.07 \\
\hline & $\mathrm{HF} \%$ & $41.6(29.1 \div 55.0)$ & $32.65(18.1 \div 49.9)$ & 0.21 \\
\hline & $\operatorname{tr}, \mathrm{s}$ & $16.01(13.49 \div 25.07)$ & $22.14(16.26 \div 28.62)$ & 0.068 \\
\hline \multirow{5}{*}{ PWC 120} & ARA & $0.092(0.06 \div 0.132)$ & $0.08(0.049 \div 0.103)$ & 0.23 \\
\hline & $\sigma s$ & $0.036(0.023 \div 0.052)$ & $0.027(0.017 \div 0.039)$ & 0.073 \\
\hline & $\mathrm{HF} \%$ & $60.6(41.7 \div 74.0)$ & $56.2(20.9 \div 69.5)$ & 0.26 \\
\hline & tr, intervals & $116.5(97.5 \div 128.5)$ & $162(122.5 \div 189)$ & 0.001 \\
\hline & tr, $\mathbf{s}$ & $84.5(70.26 \div 102.28)$ & $124.07(92.9 \div 146.8)$ & 0.001 \\
\hline
\end{tabular}

of ARA ( $\mathrm{p}=0.036)$ and $\sigma \mathrm{s}(\mathrm{p}=0.056)$ after the Valsalva maneuver. A similar trend was registered after the Ashner-Dagnini test $(p=0.07$ $\mathrm{p}=0.07$ ). According to the test with the physical loading of a person, the main group had a tendency towards higher values of $\sigma \mathrm{s}(\mathrm{p}=0.073)$ and showed a shorter recovery period $(\mathrm{p}=0.001)$ (Table 3$)$.

\section{Insights}

1. UCTD was detected in $64.2 \%$ in the study group.

2. The most important signs to diagnose UCTD are flat feet, WalkerMurdoch wrist sign, alar chest, hypermobility of thumbs, elbow joints, fingers, and Steinberg thumb sign.

3. BMI was a significantly lower in patients with UCTD.

4. Joint pain in UCTD-group was higher than in the control group.

5. Vagal influence on the heart rate regulation is increased among persons with multiple signs of UCTD.

\section{Conflict of interest}

The authors declare that there is no conflict of interest regarding the publication of this paper.

\section{References}

1. Scheper MC, de Vries JE, Verbunt J, Engelbert RHH (2012) Chronic pain in hypermobility syndrome and Ehlers-Danlos syndrome (hypermobility type): it is a challenge. J Pain Res 8: 591-601. [Crossref]

2. Zemtsovsky EV (2015) Diagnosis of inherited connective tissue disorders.Translational medicine 2: 73-82.

3. Beighton PH, Grahame R, Bird HA (1999) Hypermobility of joints, Edn.3 London Springer-Verlag, 218p

4. Folci M, Capsoni F (2016) Arthralgias, fatigue, paresthesias and visceral pain: can joint hypermobility solve the puzzle? A case report. BMC Musculoskelet Disord 17: 58. [Crossref]

5. Grahame R (2000) Pain, distress and joint hyperlaxity. Joint Bone Spine 67: 157-163. [Crossref]

6. Jason B Wheeler JB, Ikonomidis JS, Jones JA (2014) Connective Tissue Disorders and Cardiovascular Complications: The indomitable role of Transforming Growth Factorbeta signaling. Adv Exp Med Biol 802: 107-127. [Crossref]

7. Mironov VA (2017) Diagnostic noninvasive rhythmocardiography in clinicalneurocardiology. XXXII International Conference "Defectoscopia'17" Sozopol, Bulgaria. - Book of abstracts 66-71. National Recommendations of the Russian Scientific Society of Internal Medicine for diagnostics, treatment and rehabilitation of patients with connective tissue dysplasia // Medical News of North Caucasus. - 2016. 11: 1-76.

Copyright: (C2018 Akimova AV. This is an open-access article distributed under the terms of the Creative Commons Attribution License, which permits unrestricted use, distribution, and reproduction in any medium, provided the original author and source are credited. 